\title{
Acceptability of picture archiving and communication system (PACS) among hospital healthcare personnel based on a unified theory of acceptance and use of technology
}

\author{
Maryam Ahmadi ${ }^{1}$, Nahid Mehrabi ${ }^{2}$, Abbas Sheikhtaheri ${ }^{3}$, Mojtaba Sadeghi $^{4}$
}

${ }^{1} \mathrm{Ph} . \mathrm{D}$. of Health Information Management, Professor, Department of Health Information Management, School of Heath Management and Information Sciences, Iran University of Medical Sciences, Tehran, Iran

${ }^{2}$ Ph.D. Candidate of Health Information Management, Department of Health Information Management, School of Health Management and Information Sciences, Iran University of Medical Sciences, Tehran, Iran

${ }^{3} \mathrm{Ph}$.D. of Health Information Management, Assistant Professor, Department of Health Information Management, School of Health Management and Information Sciences, Iran University of Medical Sciences, Tehran, Iran

${ }^{4}$ M.Sc. Of Medical Record Education, Faculty Member, Department of Health Information Technology, School of Paramedical Sciences, Aja University of Medical Sciences, Tehran, Iran

\section{Type of article: Original}

\begin{abstract}
Background and aim: The picture archiving and communication system (PACS) is a healthcare system technology which manages medical images and integrates equipment through a network. There are some theories about the use and acceptance of technology by people to describe the behavior and attitudes of end users towards information technologies. We investigated the influential factors on users' acceptance of PACS in the military hospitals of Tehran.

Methods: In this applied analytical and cross-sectional study, 151 healthcare employees of military hospitals who had experience in using the PACS system were investigated. Participants were selected by census. The following variables were considered: performance expectancy, efforts expectancy, social influence, facilitating conditions and behavioral intention. Data were gathered using a questionnaire. Its validity and reliability were approved by a panel of experts and was piloted with 30 hospital healthcare staff (Cronbach's alpha $=0.91$ ). Spearman correlation coefficient and multiple linear regression analysis were used in analyzing the data.

Results: Expected performance, efforts expectancy, social impact and facilitating conditions had a significant relationship with behavioral intention. The multiple regression analysis indicated that only performance expectancy can predict the user's behavioral intentions to use PACS technology.

Conclusion: Performance and effort expectancies are quite influential in accepting the use of PACS in hospitals. All healthcare personnel should become aware that using such technology is necessary in a hospital. Knowing the influencing factors that affect the acceptance of using new technology can help in improving its use, especially in a healthcare system. This can improve the offered healthcare services' quality.

Keywords: PACS; Technology acceptance; Performance expectancy; Effort expectancy; Social influence
\end{abstract}

\section{Introduction}

Using information technology in a healthcare system can improve healthcare quality (1), its costs, self-care management and treatment outcomes (2). Still, several studies have indicated that hospital personnel do not easily accept new information technologies. Consequently, the services' quality is not at its highest possible standard and patients confront many problems during their treatment process which makes them unsatisfied with the healthcare system (3). The picture archiving and communication system (PACS) is a healthcare system technology. It is a

\section{Corresponding author:}

Nahid Mehrabi, Department of Health Information Management, School of health Management and Information Science, Iran University of Medical Science, Tehran, Iran.

Tel: +982188794302, Fax: +98.88772086, Email: nahmeh1@yahoo.com

Received: January 16, 2017, Accepted: June 12, 2017, Published: September 2017

iThenticate screening: June 05, 2017, English editing: August 18, 2017, Quality control: September 12, 2017

This article has been reviewed / commented by three experts

(C) 2017 The Authors. This is an open access article under the terms of the Creative Commons Attribution-NonCommercialNoDerivs License, which permits use and distribution in any medium, provided the original work is properly cited, the use is non-commercial and no modifications or adaptations are made. 
medical image management information system which manages medical images and integrates equipment through a network. Such systems allow storage of digital images in a database. Then it retrieves images using a file management server which can be transmitted to computer networks to be displayed in different resolutions. Such images can be analyzed and processed as a reference for medical treatment. Currently, PACS is becoming a standard component for radiology or hospital information system (4). It has made possible the storage management of images easier for healthcare organizations (5). New technologies are sometimes easily accepted in healthcare organizations to improve service quality and efficiency (5). Although PACS has fundamentally changed healthcare organizations, it has proven to be a real challenge for many of them $(6,7)$. Overcoming healthcare personnel's resistance in using technology and increasing its acceptance can be an obstacle to successful implementation of new technologies, such as PACS $(6,8,9)$. Although the benefits of using information technology are well documented, assessments of healthcare professionals' satisfaction of using it have proven otherwise, indicating differences of opinions (10). Implementing the best and most expensive information technology in a healthcare delivery system will be inefficient if it is resisted by the users $(4,5,10)$. Since extensive application of information technology in healthcare delivery systems can influence financial allocations, human factors such as users' acceptance will be of vital importance (9). In this regard, a commonly used system to implement and better enforce an information technology system is the information technology acceptance model. It can be used before or during execution of a new information system, to measure its level of acceptance among the target population. Indeed, these models illustrate implementation of information technology processes by assuming the factors that would draw together or independently predict their success in implementation (11). Thus, measuring acceptance is of great help in successful implementation of a system (12). Several models have been developed to study information technology acceptance, including: the tasktechnology fit model, theory of acceptance model, the unified theory of acceptance and use of technology, theory of reasoned action, theory of planned behavior and innovation diffusion (13). The unified theory of acceptance and use of technology integrates eight user acceptance models which are: theory of reasoned action, theory of planned behavior, theory of acceptance model, innovation diffusion theory, motivational model, personal computer utilization model, social cognitive theory, and a model combining the technology acceptance model and theory of planned behavior. Each of these models has an intention to determine technology use by some dependent variable. The unified theory of acceptance and use of technology aims to explain users' intentions to use an information system and their usage behavior. This theory has four main variables: performance expectancy, effort expectancy, social influence, and facilitating conditions. They are direct determinants of behavioral intention or actual use (14). Performance expectancy is the degree to which an individual believes that using the system will help him or her to gain something in job performance. Effort expectancy is the extent of convenience perceived for using a system. Social influence is the degree to which an individual perceives that important others believe he or she should use the new system (14-17). Facilitating conditions refer to the extent to which an individual perceives that technical and organizational infrastructures are required for using a system $(12,14,18)$. Behavioral intention is the possibility of a user using technology or a person's mental intention to do it. If a person uses a technology, it is called actual use (15). There is a positive relationship between the effectiveness of technology and its acceptance by the users. If potential users of a technology show resistance to its use, then the desired objectives cannot be achieved (18). In this study, we assessed the effective factors that influence the acceptance of PACS among healthcare employees of military hospitals of Tehran.

\section{Material and Methods}

This applied analytical and cross-sectional study was conducted in 2016. The study population consisted of 151 healthcare personnel that used PACS to do their tasks in five military hospitals of Tehran. We used the unified theory of acceptance and use of technology to identify factors that influence the studied users' acceptance of PACS. Data were gathered using a researcher-made questionnaire. To make the questionnaire more appropriate for this research, articles related to unified theory of acceptance and use of technology model were reviewed. The following variables were considered in this study: performance expectancy, efforts expectancy, social impact, facilitating conditions and behavioral intention. The questionnaire was divided into two parts. The first part included demographic information, which was age, sex, education, work experience, names of organization and hospital (seven items). Items of the second part were in six sub-sections: performance expectancy, effort expectancy, social influence, facilitating conditions, behavioral intention, and actual use. In all, 27 items were adapted from Davis questionnaire and resources related to the integrated model of acceptance and use of information technologies. The responses were graded as a 5-point Likert scale (from completely disagree to completely agree). Before distributing the questionnaire to the participants, its validity was confirmed by a panel of experts and its reliability was calculated by a pilot study on 30 hospital healthcare personnel using Cronbach's alpha $(\alpha=0.91)$. The data were analyzed in two parts using descriptive and inferential statistics. Descriptive statistics were used for demographic 
data and their results were presented as tables designed with Microsoft Excel software version 2010. Inferential statistics were used to investigate research questions and to determine the relationship between the variables. The studied variables were analyzed by Shapiro-Wilk test with a non-parametric Spearman correlation test because of the non-normal distribution of data. Multiple linear regression analysis was used hierarchically to identify explanatory variables of behavioral intention. The statistical package for social sciences (SPSS) software version 17 (Chicago, IL, USA) was used for data analysis.

\section{Results}

Most of our participants (63.6\%) were male. Most (39.1\%) were in the 31 to 40 years old age group. In total, $51 \%$ had a master's degree. Most (58.9\%) were assigned as radiologists. Most of our participants $(72.2 \%)$ had less than five years of experience in working with PACS and most of them (28.5\%) worked 3 or 4 days a week with this system (Table 1).

Table 1. Demographics of the studied healthcare personnel

\begin{tabular}{|c|c|c|c|c|c|c|c|c|c|c|c|c|c|}
\hline \multicolumn{2}{|l|}{ Variables } & \multicolumn{2}{|c|}{ Hospital 1} & \multicolumn{2}{|c|}{ Hospital 2} & \multicolumn{2}{|c|}{ Hospital 3} & \multicolumn{2}{|c|}{ Hospital 4} & \multicolumn{2}{|c|}{ Hospital 5} & \multicolumn{2}{|c|}{ Total } \\
\hline & & $\mathrm{n}$ & $\%$ & $\mathrm{n}$ & $\%$ & $\mathrm{n}$ & $\%$ & $\mathrm{n}$ & $\%$ & $\mathrm{n}$ & $\%$ & $\mathrm{n}$ & $\%$ \\
\hline \multirow[t]{3}{*}{ Sex } & Women & 15 & 51.7 & 14 & 41.2 & 10 & 25.0 & 4 & 25.0 & 12 & 37.5 & 55 & 36.4 \\
\hline & Men & 14 & 48.3 & 20 & 58.8 & 30 & 75.0 & 12 & 75.0 & 20 & 62.5 & 96 & 63.6 \\
\hline & $\begin{array}{l}\text { Excluded for not } \\
\text { responding to } \\
\text { questionnaire }\end{array}$ & 2 & 6.9 & 2 & 5.9 & 0 & 0 & 0 & 0 & 0 & 0 & 4 & 2.6 \\
\hline \multirow[t]{5}{*}{ Age (years) } & $<30$ & 2 & 6.9 & 10 & 29.4 & 10 & 25.0 & 1 & 6.3 & 8 & 25.0 & 31 & 20.5 \\
\hline & $30-40$ & 14 & 48.3 & 8 & 23.5 & 16 & 40.0 & 9 & 56.3 & 12 & 37.5 & 59 & 39.1 \\
\hline & $40-50$ & 7 & 24.1 & 6 & 17.6 & 6 & 15.0 & 3 & 18.8 & 4 & 12.5 & 26 & 17.2 \\
\hline & $>50$ & 1 & 3.4 & 0 & 0 & 3 & 7.5 & 0 & 0 & 1 & 3.1 & 5 & 3.3 \\
\hline & Not specified & 5 & 17.2 & 10 & 29.4 & 5 & 12.5 & 3 & 18.8 & 7 & 21.9 & 30 & 19.9 \\
\hline \multirow[t]{6}{*}{ Educational level } & Associate Degree & 4 & 13.8 & 4 & 11.8 & 4 & 10.0 & 2 & 12.5 & 4 & 12.5 & 18 & 11.9 \\
\hline & Bachelor Degree & 4 & 13.8 & 18 & 52.9 & 23 & 57.5 & 11 & 68.8 & 21 & 65.6 & 77 & 51.0 \\
\hline & Master Degree & 0 & 0 & 2 & 5.9 & 6 & 15.0 & 2 & 12.5 & 4 & 12.5 & 14 & 9.3 \\
\hline & General Practitioner & 15 & 51.7 & 0 & 0 & 0 & 0 & 0 & 0 & 0 & 0 & 15 & 9.9 \\
\hline & $\mathrm{PhD}$ & 5 & 17.2 & 1 & 2.9 & 7 & 17.5 & 0 & 0 & 3 & 9.4 & 17 & 11.3 \\
\hline & Not Specified & 1 & 3.4 & 9 & 26.5 & 0 & 0 & 1 & 6.3 & 0 & 0 & 11 & 6.6 \\
\hline \multirow[t]{7}{*}{ Occupation } & Dentist & 21 & 72.4 & 0 & 0 & 0 & 0 & 0 & 0 & 0 & 0 & 21 & 13.9 \\
\hline & Nurse & 1 & 3.4 & 16 & 47.1 & 0 & 0 & 0 & 0 & 8 & 25 & 25 & 16.6 \\
\hline & Radiology technician & 4 & 13.8 & 7 & 20.6 & 40 & 100 & 16 & 100 & 22 & 68.8 & 89 & 58.9 \\
\hline & Social worker & 0 & 0 & 7 & 20.6 & 0 & 0 & 0 & 0 & 0 & 0 & 7 & 4.6 \\
\hline & Anesthesiologist & 0 & 0 & 1 & 2.9 & 0 & 0 & 0 & 0 & 0 & 0 & 1 & 0.7 \\
\hline & Other & 1 & 3.4 & 0 & 0 & 0 & 0 & 0 & 0 & 0 & 0 & 1 & 0.7 \\
\hline & Emergency physician & 0 & 0 & 1 & 2.9 & 0 & 0 & 0 & 0 & 2 & 6.2 & 3 & 6.2 \\
\hline \multirow{4}{*}{$\begin{array}{l}\text { Work experience } \\
\text { with PACS (year) }\end{array}$} & $<5$ & 22 & 75.9 & 22 & 64.7 & 26 & 65.0 & 14 & 87.5 & 25 & 78.1 & 109 & 72.2 \\
\hline & $5-10$ & 1 & 3.4 & 5 & 14.7 & 11 & 27.5 & 1 & 6.3 & 4 & 12.5 & 22 & 14.6 \\
\hline & $10-15$ & 0 & 0 & 0 & 0 & 0 & 0 & 0 & 0 & 2 & 6.3 & 2 & 1.3 \\
\hline & Not specified & 6 & 20.7 & 7 & 20.6 & 3 & 7.5 & 1 & 6.3 & 1 & 3.1 & 18 & 11.9 \\
\hline \multirow{6}{*}{$\begin{array}{l}\text { Number of days } \\
\text { per week working } \\
\text { with PACS }\end{array}$} & None & 1 & 3.4 & 2 & 5.9 & 2 & 5.0 & 4 & 25.0 & 2 & 6.3 & 11 & 7.3 \\
\hline & $1-2$ & 7 & 24.1 & 11 & 32.4 & 6 & 15.0 & 1 & 6.3 & 1 & 3.1 & 26 & 17.2 \\
\hline & $3-4$ & 3 & 10.3 & 10 & 29.4 & 19 & 47.5 & 3 & 18.8 & 8 & 25.0 & 43 & 28.5 \\
\hline & $5-6$ & 7 & 24.1 & 3 & 8.8 & 5 & 12.5 & 1 & 6.3 & 8 & 25.0 & 24 & 15.9 \\
\hline & 7 & 9 & 31.0 & 7 & 20.6 & 7 & 17.5 & 6 & 37.5 & 13 & 40.6 & 42 & 27.8 \\
\hline & Not specified & 2 & 6.9 & 1 & 2.9 & 1 & 2.5 & 1 & 6.3 & 0 & 0 & 5 & 3.3 \\
\hline
\end{tabular}

The Shapiro-Wilkin test showed that the variables were not distributed normally. So Spearman's correlation coefficient was used to examine the relationships between variables (Table 2). All variables had a positive, significant correlation with behavioral intention. The highest correlation coefficient belonged to performance expectancy $(\mathrm{p}<001, \mathrm{r}=0.56)$ and the lowest correlation coefficient belonged to facilitating conditions $(\mathrm{p}<0.01$, $\mathrm{r}=0.232$ ). The hierarchal multiple linear regressions were used to determine the variables' roles in predicting behavioral intention. PACS which was an influential grounded variable was coded as four dummy variables, and entered the regression equation in the first block. Performance expectancy, effort expectancy, social influence and facilitating conditions entered the regression equation as the second block in a stepwise manner. Performance 
expectancy was the only significant variable of the second block that entered the regression equation (Table 3 ). Using PACS determined $13 \%$ of the behavioral intention variance $(p<0.001)$. Performance expectancy determined $47.6 \%$ of behavioral intention variance $(\mathrm{p}<0.001)$. Standardized regression coefficient of performance expectancy was $B=0.72(p<0.001, t=13.0)$. Squared adjusted correlation of regression model was $0.59(p<001, F=43.04)$.

Table 2. Studied variables correlation with behavioral intention

\begin{tabular}{|l|l|l|}
\hline Variable & Correlation & $\mathrm{p}$-value \\
\hline $\begin{array}{l}\text { Performance } \\
\text { expectancy }\end{array}$ & 0.56 & 0.001 \\
\hline Effort expectancy & 0.454 & 0.001 \\
\hline $\begin{array}{l}\text { Social } \\
\text { influence }\end{array}$ & 0.353 & 0.001 \\
\hline $\begin{array}{l}\text { Facilitating } \\
\text { condition }\end{array}$ & 0.232 & 0.004 \\
\hline Using PACS & 0.362 & 0.001 \\
\hline
\end{tabular}

Table 3. The main outcomes of multiple linear regressions of the studied variables

\begin{tabular}{|l|l|l|l|l|l|}
\hline Variable & $\mathrm{R}^{2}$ & $\mathrm{~F}$ & Freedom degree 1 & Freedom degree 2 & P value \\
\hline Frequency of Using PACS & 0.13 & 5.266 & 4 & 141 & 0.001 \\
\hline Performance expectancy & 0.476 & 169.059 & 1 & 140 & 0.001 \\
\hline
\end{tabular}

* Justified $\mathrm{R}^{2}=0.59 ; \mathrm{F}=43.04 ; \mathrm{P}<0.001$

\section{Discussion}

This study investigated the influencing factors of accepting the use of PACS technology in military hospitals of Tehran by the healthcare personnel. The results showed that performance expectancy and facilitating conditions have the most and least relationship with behavioral intention to use their PACS, respectively. Our study showed that performance expectancy has a significant effect on user's behavioral intention. If the user feels that using PACS can improve his/her performance, she/he will have more motivation for using it. This is in line with Venkatesh and colleagues (14), Davis and colleagues (15) and Gupta and colleagues' (19) findings. Similarly, Chang and colleagues showed the significant impact of performance expectancy on using a pharmacokinetics decision support system in 140 physicians (20). Also, Gravand and colleagues found a positive relationship between attitude towards usefulness and attitude towards using PACS system in hospitals of Shiraz city, Iran (21). Langarizadeh and colleagues found a significant association between users' perception of usefulness and their decision to use the hospital information system (22). Goudarzvand and colleagues studied the impact of organizational culture by adopting an integrated model of acceptance, and use of information technology in hospitals of Rasht city, Iran. They found a significant association between perception of usefulness and using computers (23). Their population consisted of healthcare, administrative, financial and educational employees while we have only studied the healthcare personnel. Based on the unified theory of acceptance and use of technology, Al-Awadhi and Morris discovered that students' performance expectancy of the Kuwait's governmental electronic services has a significant impact on using those systems (24). Duyck and colleagues investigated radiologists and physicians' acceptance of PACS at a hospital in Belgium using unified theory of acceptance and use of technology before and after its implementation. Performance expectancy was an important factor in predicting user's behavior intention in using PACS (25). All these studies are consistent with ours in that performance expectancy is significantly related to behavioral intention. Our study showed that effort expectancy has a significant effect on user's behavioral intention. So if the users can use a technology easily, they are more willing to use it. Davis and colleagues (15), Venkatesh and colleagues (14) and Gupta and colleagues (19) have all found such a relationship in different studies based on the unified theory of acceptance and use of technology. In a study based on technology acceptance model, Tung and colleagues stated that ease of use is very influential in actual use of information systems in medical industry (26). Also, Ghlandari achieved the same results in investigating acceptance of electronic banking services among customers based on a unified theory of acceptance and use of technology. His intervening variables were age and sex (27). Our study showed that social influence has a significant effect on user's behavioral intention. This shows that managers and employers or influential peers' use of a technology can influence employees to use that technology. In a similar study, Wu and colleagues found social norms as the most influential factor in employees' decision to use an electronic reporting system for side effects (28). Aggelidis and Chatzoglou concluded that social norms are related to the decision to use an information system (3). Carlsson and colleagues found a significant relationship between social norms and decision to use mobile services for answering surveys (29). However, Duyck and colleagues did not find a significant relationship between social norms and the decision to use PACS (25). Our 
study showed that facilitating conditions have a significant effect on users' behavioral intention. This is in line with the findings of Aggelidis and Chatzoglou (3) and Duyck and colleagues' (25) studies. Also, according to Attuquayefio and Addo's findings, facilitating conditions have a positive effect on the students' use of information and communication technologies (30). However, Langarizadeh and colleagues did not find a significant relationship between facilitating conditions and user's behavioral intention (22). Our study showed that behavioral intention has a significant effect on the actual use of that system. In line with our finding, Ghalavandi found out teachers' behavioral intention for using computers has a significant effect on their actual use (31). Also, Ghlandari found that bank customer's behavioral intention for using computers has a significant effect on their actual use (27). A limitation of our study was that the full capacity of PACS is not used in the studied hospitals, although there has been high expenditure in establishing the system. So the studied healthcare personnel did not know all the potentials of this system.

\section{Conclusions}

Performance expectancy, effort expectancy, social influence and facilitating conditions have a significant association with behavioral intention among hospital healthcare employees. However, the multiple linear regression analysis showed that only performance expectancy has the potential to predict behavioral intention. Each of the studied variables is influential in the decision to use PACS and should be considered by medical centers' authorities to successfully implement PACS. Training healthcare personnel in using PACS seems necessary. It is recommended that further studies be conducted on the acceptance of using healthcare technology systems, such as PACS, based on structural equation models and technology acceptance models.

\section{Acknowledgments:}

This study was part of a research project supported by Iran University of Medical Sciences (Grant No: 95-01-13527251). The authors would like to thank Seyed Muhammed Hussein Mousavinasab for his sincere cooperation in editing this text.

\section{Conflict of Interest:}

There is no conflict of interest to be declared.

\section{Authors' contributions:}

All authors contributed to this project and article equally. All authors read and approved the final manuscript.

\section{References:}

1) Schaper LK, Pervan GP. ICT and OTs: A model of information and communication technology acceptance and utilisation by occupational therapists. International Journal of Medical Informatics. 2007;76:S212-21. doi: 10.1016/j.ijmedinf.2006.05.028, PMid: 16828335

2) Blumental D. Launching Hi-tech. New England Journal of Medicine. 2010;362(5):382-5. DOI: 10.1056/NEJMp0912825

3) Aggelidis VP, Chatzoglou PD. Using a modified technology acceptance model in hospitals. International Journal of Medical Informatics. 2009;78(2):115, doi: 10.1016/j.ijmedinf.2008.06.006, PMid: 18675583

4) Aldosari, B. User acceptance of a picture archiving and communication system (PACS) in a Saudi Arabian hospital radiology department. BMC Medical Informatics and Decision Making. 2012. 12:44. DOI: $10.1186 / 1472-6947-12-44$

5) OECD: Improving Health Sector Efficiency: The Role of Information and Communication Technologies. Paris: OECD Health Policy Studies; 2010. Available from: http://ec.europa.eu/health/eu_world/docs/oecd_ict_en.pdf

6) Pare G, Trudel MC: Knowledge barriers to PACS adoption and implementation in hospitals. International Journal of Medical Informatics. 2007; 76(1):22-33. DOI:10.1016/j.ijmedinf.2006.01.004

7) Honeyman-Buck J: PACS adoption.Seminars in Roentgenology.2003; 38(3):256-269. DOI: 10.1016/S0037-198X(03)00045-2

8) Bramson RT, Bramson RA. Overcoming obstacles to work-changing technology such as PACS and voice recognition. American Journal of Roentgenology. 2005; 184)6):1727-1730. DOI: 10.2214/ajr.184.6.01841727

9) Ward R, Stevens C, Brenthall P, Briddon J: The attitudes of health care staff to information technology: a comprehensive review of the research literature. Health Information and Libraries Journal. 2008, 25(2):8197. DOI: $10.1111 / \mathrm{j} .1471-1842.2008 .00777 . x$. 
10) Buntin MB, Burke MF, Hoaglin MC, Blumenthal D. The benefits of health information technology: a review of the recent literature shows predominantly positive results. Health Aff.2011; 30(3):464-471. DOI: 10.1377/hlthaff.2011.0178.

11) Tsiknakis M, Kouroubali A. Organizational factors affecting successful adoption of innovative e Health services :a case study employing the FITT frame work. International Journal of Medical Informatics. 2009;78(1):39-52. DOI: 10.1016/j.jmedinf.2008.07.001

12) Holden RJ, Karsh BT. The technology acceptance model: its past and its future in health care. Journal of Biomedical Informatics. 2010;43(1):159-72. DOI: 10.1016/j.jbi.2009.07.002.

13) Wills MD, El-Gayar OF, Bennett D. Examining healthcare professionals' acceptance of electronic medical records using UTAUT. Issues in Information Systems.2008;9(2):396-401.

14) Venkatesh V. Morris M, Davis G, Davis F. User acceptance of technology: Toward a unified view.MIS Quarterly.2003;27(3): 425-478.

15) Davis FD, Bagozzi, RP, Warshaw PR. User acceptance of computer technology: A comparison of two theoretical models. Management Science.1989;35(8): 982-1003. doi: 10.1287/mnsc.35.8.982

16) Thompson RL, Higgins CA, Howell JM. Personal Computing: toward conceptual model of utilization. Management Information system Quarterly. 1991;15(1): 125-143. DOI: 10.2307/249443

17) Moore GC, Benbasat IB. Development of an instrument to measure the perceptions of adopting an innovation technology innovation. Information Systems Research.1991;2(3):192-222. doi: 10.1287/isre.2.3.192

18) Ammenwerth E, Gräber S, Herrmann G, Bürkle T, König J. Evaluation of health information systems problems and challenges. International Journal of Medical Informatics. 2003;71(2-3):125-35. DOI: 10.1016/S1386-5056(03)00131-X

19) Gupta B S D, Gupta A. Adoption of ICT in a government organization in a developing country: An empirical study. Journal of Strategic country: An empirical study. Journal of Strategic Information Systems 2008;17(2):140-154. DOI: 10.1016/jsis.2007.12.004

20) Chang I C, Hwang H G, Li Y C. Physicians acceptance of pharmacokinetics-based clinical decision support systems. Expert Systems with Applications 2007;23: 296-303. DOI: 10.1016/jeswa.2006.05.001

21) Gravand A, Ganbari sh, Ebrahhimi S, kafashi M, Ahmadzade F. The effective factors in adopting picture archiving and communication system in Shiraz educational hospitals based on technology acceptance model in 2015.Health and Biomedical informatics 2015;1(2):76-82.

22) Langarizadeh M, Gohari M, Koohestani A. Acceptance of Hospital Information System among Medical Records Users Based on Technology Acceptance Model. Health Info manage.2014;10(2):800-9.

23) Ghodarzvand ghegini M, Esmaeeli S.The study of organizational culture associated with unified theory of acceptance and use of technology in hospital of Rasht 2015;9(1):29-42.

24) Al-Awadhi S, Morris A. The use of the UTAUT model in the adoption of e-government services in Kuwait. Proceedings of the 41st Hawaii International Conference on System Sciences. 2008. DOI: 10.1109/HICSS.2008.452

25) Duyck P, Pynoo B, Devolder P, Voet T, Adang L, Ovaere D, Vercruysse J. Monitoring the PACS Implementation Process in a Large University Hospital-Discrepancies Between Radiologists and Physicians . Journal of Digit Imaging 2010; 23(1): 73-80. DOI: 10.1007/s10278-008-9163-7.

26) Tung FC, Chang SC, Chou CM. An extension adoption of trust and TAM model with IDT in the adoption of the electronic logistics information system in HIS in the medical industry. Int J Med Inform 2008;77(5): 324-35. doi: 10.1016/j.ijmedinf.2008.07.006

27) Ghalandari K. The Effect of Performance Expectancy, Effort Expectancy, Social Influence and Facilitating Conditions on Acceptance of E-Banking Services in Iran: the Moderating Role of Age and Gender. MiddleEast J. Sci. Res. 2012;12 (6): 801-807.

28) $\mathrm{Wu} \mathrm{JH}$, Shen WS, Lin LM, Greenes RA \& Bates DW. Testing the technology acceptance model for evaluating healthcare professionals' intention to use an adverse event reporting system. International Journal for Quality in Health Care 2008;20(2): 123-9. DOI: 10.1093/intqhe/mzm074.

29) Carlsson, C.H, Carlsson J, Hyvönen K, Puhakainen J. Walden P. Adoption of mobile devices/services searching for answers with the UTAUT Proceedings of the 39th Hawaii International Conference on System Sciences. (CD-ROM); 2006 Jun 4-7; Kauai, HI, USA Computer Society Press 2006.p.10 pages.

30) Attuquayefio SN, Addo H. Using the UTAUT model to analyze students' ICT adoption. IJEDICT. 2014; 10(3):75-86

31) Ghalavandi H. Factors affecting the use of computers among teachers test of integrated theory and technology acceptance. New thoughts on education journal. 2015; 11(3):11-27. 